when a sufficient amount of open water appears, to make the passage a reasonable certainty, and the date for this year I place at from July 5 to 15 , as it is more than likely that a ship could have got through the Straits in ten days. The ice is, moreover, so sensitive to wind that even if telegraph stations were so placed as to be able to convey to ships news regarding the position of the ice ahead, long before the ves el arrived at the place the condition of affairs might, and probably would, be totally changed.

As to the closing of navigation in $1884, \mathrm{Mr}$. Laperrière reports, at Cape Digges, that on October 25 the ice was solid in every direction, and at Nottingham Island a similar entry is made on the 27th. A distinction must be made between the closing of navigation by the formation of young ice, and the presence of a large field of heavy old ice which is cemented together by the formation of young ice between the pans. In the first ca:e any ordinarily powerful steamer could go through without risk, but in the second case the most powerful of the whaling or sealing steamers would be helpless. The western end of the Straits is always subject to incursions of this heavy ice, from Fox Channel, and especially so in the months of September and October, when strong north-easterly and northwesterly gales are frequent, and we have now evidence that in both seas ${ }^{2}$ s, 1884 and 1885 , this heavy ice came down in October.

As to the length of season for practical navigation, if we regard the presence of field ice as the only barrier, the information which we have got would point to the months of July, August, September, and October as being the months in which the Straits are passable. As a rule, in July there will be delays, but to vessels strengthened and sheathed there would be no danger in making the passage.

All the inhabitants of the Labrador, the Straits, and the Bay, spoken to on the subject, agreed in stating that the ice movements this year were much later than the average; at Fort Churchill the season was fully a month late, and on the Labrador three weeks, so that I think it will be found that on the average four months will be the length of the season for practical navigation by steam vessels which would be freight-carriers. There have been, I am informed, seasons when the Straits were clear of ice in the month of June, but they are, according to the logs of the Hudson's Bay ships, quite exceptional. Captain Hawes spoke of such being the case only once in his experience of fourteen years, and the dates which I have seen of the arrival of the Hudson's Bay vessels at their ports of destination show no arrival earlier than $A$ ugust.

\section{THE TRANSCASPIAN FAUNA}

WE notice in one of the last issues of the Bulletin of the Moscow Society of Naturalists (1885, No. 2) a most valuable paper, by M. Zaroudnoi, on the birds of the Transcaspian region. His list contains an enumeration of 184 species, well determined on 600 specimens-doubts remaining only with regard to a very few species. The author distinguishes in the region the following chief zoological sub-regions:-(I) The Kara-kum desert, having a pretty well furnished flora, notwithstanding its immense sandy plains and salt clays. The Tamarix forests, now mostly destroyed, are well peopled with the Atraphornis aralensis, as also with a few Podoces (Panderi?) and Passer (ammodendri?), which make their nests further north in the saksaul forests. The Houbara quennii, Gray, is rare. The reptiles are represented by the Phrynocephalus interscapularis and helioscopus, Agama sanguinolenta, Testudo, Naja oxiana, Eichwald; the Varanus sciucus extends much further south into the Akhal-Tekke plain, and even to the Kopet-dagh Mountains. (2) The Akhal-Tekke oasis, striking by the monotony of its landscape, diversified only by the gardens of the Tekkes, which remain green even during the hottest part of the summer, when all vegetation is scorched up by the sun. In the plain only the Tamarix, a few willows on the banks of the rivulets, and the dark-green bushes of the capers, adorned with pretty flowers, are to be seen. The great areas covered with bushes of Alchagi camelorum and wormwood increase the monotony of the landscape. Pretty Fulodis variolarius, eufraticus, and sometimes globicollis are often found flying around these bushes; in July the Fisheria baetica, Ramb., several Irises, as also Empus pennicornis, Pall., several kinds of Ateuchus and Copris, and numerous species of Melanozomata are met with. The stone-chatters (traquets) and larks are so numerous as to become troublesome. The Phrynocephalus helioscopus and Agama sanguinolenta fly at the approach of man. From time to time a dscheiran, or a fox, may be perceived. The nights are sultry and hot, and one hears the shrivelling of the Grillus cerisyi, Serv., and G. capensis, Fabr., the barking of the jackals, and the cries of Caprimulgus arenicolor. Sev. The banks of the few rivers, covered with brush and reed-grass, are the refuge of the wild cat and the Lagomy's. The high summer temperature of the oasis is well known : $40^{\circ}$ Cels. in the shade being not uncommon; and M. Zaroudnoi is inclined to ascribe to the great heat the intensity of the moulting of birds. The lark loses so much of its feathers that the body remains in many parts quite naked; with the stone-chatters only the base of the feathers remains on their heads. Most of the birds met with in the oasis during the summer belong to the Aral-Caspian fauna, the others come from the mountains; these last have followed the courses of the rivers and have taken possession of the AkhalTekke gardens; such are the Salicipasser montanus, Passer indicus, Sylvia mystacea, Butalis grisola, a great number of Salicicarice, and several others. Some, like the griffons, the ravens, the Cypselus apus, the Chelidon urbica, the Merops apiaster, inhabit the mountains, and descend to the plain only for bunting. The Galerita magna, Calandrella pispoleta, and Saxico'a isabellina, may be considered as representatives of the Akhal-Tekke fauna owing to their considerable numbers. (3) The mountain-region is much more interesting, especially when the traveller reaches the upper valleys covered with forests, where the vines grow wild. Wild cats and jackals are the usual inhabitants of these valleys; but the Cynailurus jubatus and the Leopardus pardus are rare; L. irbis is never met with in the region. Hyana striata is occasionally met with. Ellobis talpinus, several Erinaceus and Platycercomys, as also Histrix hirsutirostrix are common. The dreadful Vipera eufratica is a source of continual danger during the grape-harvest. Eremias velox and Agama sanguinolenta are worthy of notice. As to the birds, we must merely refer to the list of M. Zaroudnoi, where notes as to their distribution are given in French. The zoological determinations have been revised by M. Menzbier.

\section{SOCIETIES AND ACADEMIES}

\section{LONDON}

Royal Society, May 27.-. "Researches in Stellar Photography." By the Rev. Prof. Pritchard, F.R.S.

The objects of these researches are:-(I) To ascertain, if possible, by means of definite and accurate measurement, as distinguished from impressions and estimates, what is the relation between the diameter of a star-disk impressed on a photographic plate with a given exposure, and its photometric magnitude, instrumentally determined. With this view, five plates of the Pleiades were taken with different exposures, on different nights. The diameters of the star-disks on each of the plates were then measured with a double-image micrometer, checked by measurement also with the macro-micrometer in the Oxford University Observatory. Curves were then drawn for each of the plates, taking the magnitudes as given in the "Uranometria Nova Oxoniensis" as abscissæ, and the measured diameters as ordinates. The result was a satisfactory coincidence in the case of all the plates, leading, when treated in the usual manner, to the final result-

$$
D-D^{\prime}=\delta\left\{\log M^{\prime}-\log M\right\}
$$

where $D, D^{\prime}$ are the measured diameters of any two stars on the plate, and $M, M^{\prime}$ the corresponding photometric magnitudes; $\delta$ being a definite constant depending on the physical circumstances of the particular plate.

It was observable that, out of twenty-eight stars examined, three stood out from the rest, indicating, as might have been expected, some peculiarity in the spectra of these stars. In the memoir itself the tabular relations of all the measures are exhibited. The similarity of the symbolical form above to the relations existing between "magnitude" and intensity of light is obvious and interesting.

(2) Another branch of the inquiry is still more important, and it is this. Seeing that in the modern use of the dry plates the times of exposure are so considerable, and the processes of development and drying, \&c., so suspiciously dangerous to the stability of the films, it becomes a matter of great importance to ascertain 
whether the photographic plate remains an absolutely accurate picture of the actual relative positions of the stars in the sky itself, and, moreover, whether these are measurable with that extreme degree of precision which is attainable with the best instrumental means. To ascertain this, the same plates for a portion of the Pleiades were taken which gave rise to the formula already obtained. The distances of some twenty-five of the stars from Alcyone were measured on each of these plates, the number of repetitions of the measures being made the same as those adopted by Bessel in his measures of the same distances with bis heliometer. The resulting accordances of these individual measures on each of the plates was very satisfactory, and a trifle better than the accordances in the case of Bessel's measures and the accordance of each of the means of the distances of each of the stars from Alcyone on each plate was at least quite equal to the results obtained with the heliometer. The average deviations from the mean for all the measures was, in the case of the photographic plates, $\mathrm{O}^{\prime \prime} \cdot 24$, and, of the heliometer measures, $0^{\prime \prime} \cdot 29$. These satisfactory accordances of the resulting measures on each of the plates (corrected for refraction, and where necessary for aberration), afford a sure indication of the reality of the pictures, as well as of their accurate measurability.

An interesting circumstance occurred in the course of the work. On one of the plates the distances of three stars from Alcyone exhibited a slight discordance of from $\mathrm{O}^{\prime \prime} \cdot 75$ to $\mathrm{I}^{\prime \prime} \cdot 5$, when compared with those stars on the other plates. These three stars all occupied a small area on the plate; no discordances occurred on this plate with respect to any of the other stars. Here is an indication of a slight disturbance of the film on one small portion of the plate, but on no other portion. Hence the necessity of the precaution of taking at least three plates for the purpose of security of measurement. The plates were exposed variously for about 8 to 12 minutes in the focal plane of the de la Rue reflector of 13 inches aperture

(3) A few stars were examined on the same plate with different exposures, varying from I second to I 20 , with the view of ascertaining, if possible, the relation between the areas of the impressed star-disks and their time of exposure. As far as at present appears, these areas vary as the square root of the time. This result differs widely from that obtained by Bond in 1858 . That as ronomer con-idered that these areas varied directly as the time; the investigation, however, is not yet complete, and will be resumed at Oxford. It is well known that these photographic disks are not sharply and definitely cut circles on the negative plate, when examined with the higher powers of the microscope, such as 100 and beyond; but they are fringed with a number of discreet black dots extending to some distance beyond the hard photographic images. Nevertheless, these images, when printed in the form of pasition, lose this fringe, and preient the appearance of well-defined sharply-cut circles the light appears to have penetrated through the interstices of the discrete fringe, and leaves a very definite outline. Encouraged by these results of the measurements of the stars from Alcyone, I propose to test this photographic method still further by applying it, not without hope of success, to the question of stellar parallax.

These measures are now well advanced, and afford good hope of success.

Chemical Society, June 17.-Dr. Hugo Müller, F.R.S., President, in the chair.- The following were elected Fellows of the Society:- Thomas Akitt, James Blake, M.D., Alfred Chaston, A. W. H. Chapınan, Iugusto Cæsar Diojo, Charles A. R. Jowitt, Charles Alexunde: Kohn, John Temple Leow, Willia!n Ray, Joseph Price R mington, William Richards, Forbes Rickard, Willian Saunlers, Charles A. Smith. - The following papers were rea $1:-$ The electrolysis of aqueous solutions of sulphuric acid, with - jecial reference to the forms of oxygen obtained, by Prof. H. McLeod, F.R.S.-Essential oils (Part III.): their specific refractive and dispersive power, by Dr. J. H. Gladstone, F.R.S. - The formation and destruction of nitrates and nitrites in artificial solutions and in river and well waters, by J. M. II. Munro, D.Sc. - Water of crystallisation, by W. W. J. Nicol, M. A., D.Sc., F.R.S.E.-A method of investigating the constitution of azo-, diazo-, and analogous compounds, by R. Meldola, F.R.S., and F. W. Streatfeild. The estimation of free oxygen in water, by Miss K. I. Williams and Prof. W. Ram ay. - Note as to the existence of an allo tropic modification of nitrogen, by Miss K. I. Williams and Prof. Ramsay. - The presence of a reducing agent, probably hydrogen peroxide, in natural water, by Prof. Ramsay. - Evaporation and dissociation ('art IV.); a study of the thermal properties of acetic acid, by W. Ramsay, Ph.D., and Sydney Young, D.Sc.- Note on the vapour-densities of chloral ethylalcoholate, by William Ramsay, Ph.D., and Sydney Young, D.Sc. - The nature of liquids as shown by a study of the thermal properties of stable and of dissociable bodies, by William Ramsay, Ph.D., and Sydney Young, D.Sc.-The electromotive forces developed during the combination of cad. mitum and iodine in presence of water, by A. P. Laurie, B.A., B.Sc.-Detection and estimation of iodine, bromine, and chlorine, by M. Dechan. - The analysis of alloys and minerals containing the heavy metals, selenium, tellurium, \&c., by Thomas Bayley.

Entomological Society, July 7. - Mr. J. Jenner Weir, F.L.S., Vice-President, in the chair-Mr. S. H. Scudder, of Cambridge, Mass., U.S., was elected a Foreign Member of the Society.-The Rev. H. S. Gorham exhibited specimens of Eucnemis capucina, Ahr, a species new to Britain, discovered in June last in an old beech tree in the New Forest. $\mathrm{He}$ also exhibited specimens of Cassida chloris.-Dr. Sharp exhibited larvæ of Meloë, and read notes on their habits, and Mr. Saunders exhibited a specimen of Haliclus infested with about thirty Meloë larvæ. Mr. Billups remarked that he had recently found fortyseven larva of Meloë on the body of a species of Eucera. Dr. Sharp said that he was of opinion that the operations of these larva were not the re:ult of instinct, but were more like reflex actions: the instant the larvæ touched a suitable surface they clung to it. The discussion was continued by Prof. Riley, who disagreed with Dr. Sharp, and believed these larv $x$ were guided by instinct, as they showed a decided preference for particular hosts. - Mr. Jenner Weir exhibited a male of Lycena bellargus and a female of $L$. icartus, which had been captured in copula by Mr. Hillman, and shown to the exbibitor at the time of capture. Mr. Weir also exhibited some specimens of Lycena which he believed to be hybrids between L, cana bellargus and L. icarus; and he further exhibited, on behalf of Mr. Jenner, four specimens of Phosphenus hemipterus, taken at Lewes. - The Rev. W. W. Fowler exhibited two specimens of Chrysomela cercalis, lately taken by Dr. Ellis on Snowdon; and also two specimens of Actocharis Readingii, found at Falmouth by Mr. J. J. Walker.Mr. E. B. Poulton called attention to the fact that the larvæ of some Lepidoptera, if fed in captivity on an unusual food-plant, subsequently refused to eat their ordinary food-plant. He stated that he had observed this with the larvæ of Pygara bucephala and Smerinthus ocellatus. Mr. Stainton, Mr. Fowler, and Mr. Goss made some remarks on the subject. -Mr. Elisha exhibited a series of bred specimens of Geometra smaragdaria.-M. Alfred Wailly exhibited a long series of silk-producing moths, including some remarkable hybrids between $P$. cecropia and $P$. ceanothi; and Prof. Riley and Mr. Weir made some observations on these hybrids.-Dr. Shurp read a paper on Eucnemis capucina (Ahr.) and its larva.-Mr. Dunning read a report on the subject of the importation of humble-bees into New Zealand, from which it appeared that the efforts of $\mathrm{Mr}$. Nottidge, of Ashford, and the Canterbury (N.Z.) Acclimatisation Society had been successful, and that the long wanted clover-fertiliser had at length been established in New Zealand.-M. Peringuey communicated notes on some Coleopterous insects of the family Paussida.-Mr. J. B. Bridgman communicated additions to the Rev. T. A. Marshall's Catalogue of British Ichneumonidæ,-Prof. Riley read notes on the phytophagic habit, and on alternation of generation, in the genus Isosoma. In this paper Prof. Riley described, from direct observation, the phytophagic habit in two species of the genus. He also established the existence of alternation of generation.

\section{EDINBURGH}

Royal Society, July 5.-The Hon. Lord Maclaren, VicePresident, in the chair. - In a paper on the electrical resistance of nickel at high temperatures, Prof. C. G. Knott, of Tokio University, gave an account of experiments on certain nickel wires, in which the temperature was carried to a fairly bright red head. The resistance at different temperatures was compared with the resistance of a platinum wire at the same temperatures; and, by the substitution of other metals for the nickel, further comparisons were established. Nickel, platinum, palladium, and iron were thus studied; and the general conclusions were as follows:--(I) The rate of growth of the resist. 
ance of a given nickel wire with temperature is greater, on the average, than the corresponding quantity for platinum or palladium, and less than that for iron. (2) The "logarithmic rate" - that is, the rate of change per unit rise of temperature of unit resistance at any temperature-falls off more slowly for nickel as the temperature rises to $200^{\circ} \mathrm{C}$. than for platinum or palla. dium. (3) At about $200^{\circ} \mathrm{C}$. the rate of resistance growth for nickel increases markedly, and continues practically steady, till about $320^{\circ} \mathrm{C}$., when a sudden decrease occurs, and thereafter the resistance steadily increases at this diminished rate. In other words, between the limits of temperature specified, the slope of the resistance curve is much steeper than for any other. The same peculiarity is probably possessed by iron between the temperatures of a dull red and a bright red heat. (4) The peculiarity occurs (in each case) between the limits of temperature within which the striking thermo-elec tric peculiarity discovered by Tait also occurs. This peculiarity, which is most briefly described as an abrupt change in the sign of the Thomson effect, is not known to be possessed by any other metal. (5) There is thus a strong presumption that the Thomson effect in metals has a close connection with the mutual relations of resistance and temperature-at any rate in metals in which the Thomson effect is proportional to the absolute tem perature (according to Tait's theory) the "logarithmic rate" of change of resistance seems to be very approximately inversely as the absolute temperature. In nickel and iron, in which the law of the Thomson effect is peculiar, such a simple relation between resistance and temperature does not hold.-Prof. Tait discussed the effect of external forces on a system of colliding spheres. He gave a proof, much more simple than Maxwell's, of the fact that gravity has no effect in altering a uniform distribution of temperature throughout a vertical gaseous column. His proof is founded on the assumption that, in a horizontal layer of gas which has arrived at a steady state, all particles passing acros. the upper surface do so on the whole as if they had freely passed through the layer.-Dr. John Murray read a paper by Dr. H. B. Guppy on the mode of formation of the coral reefs of the Solumon Islands. In this paper the typical reefs were described with the various corals growing on them. In places exposed to the full sweep of the trade-winds the corals do not grow higher than to about 7 or 10 feet from the surface. In sheltered places they are found at a depth of from 4 to 5 feet. Dr. Guppy believes that the reefs never ri-e to the surface without upheaval. $\mathrm{He}$ gives a theory of the construction of barrier reefs, which corresponds to that formerly given by Le Comte to explain the reefs of Florida.--Mr. J. T. Cunningbam, of the Scottish Marine Station, read a paper on the eggs and early stages of some teleosteans, and also a paper on the reproductive organs of Bdellostoma, and a teleostean egg from the West Coast of Africa.-Mr. Patrick Geddes gave a synthetic outline of the history of biology, and also read a paper on the theory of growth, reproduction, heredity, and sex.

\section{SYDNEY}

Linnean Society of New South Wales, May 26.-Prof. W. J. Stephens, M.A., F.G.S., in the chair.-The following papers were read:--Notes on some Australian Tertiary fossils, by Capt. F. W. Hutton. In this paper, which is based on the examination of a fine collection of Australian Tertiary fossils recently sent to the Canterbury Museum by Prof. Tate of Adelaide, Capt. Hutton enumerates seventeen species of molluses and echinoterms which are common to the Tertiary strata both of Australia and New Zealand, and deals with their synonymy. -On some further evidences of glaciation in the Australian Alps, by James Stirling, F.L.S., communicated by C. S. Wilkinson, F.G.S. After reviewing what has been written on the subject of glacial action in Australia, the author adduces fresh evidence in favour of such action, obtained by himself and Dr. Lendenfeld during a recent visit to Mount Bogong, the
highest mountain in Victoria, where erratics, perched blocks, smoothed surfaces, and old moraines were met with. - Jottings from the Biological Laboratory, Sydney University, by W. A. Haswell, M.A.: (No. 7) On a method of cutting sections of delicate vegetable structures; (No. 8) on the vocal organs of the Cicada.-Mount Wilson and its ferns, by P. N. Trebeck. Mr. Trebeck describes the position, geology, soil, and vegetation generally of Mount Wilson, and gives details of 15 genera of ferns, including $3^{8}$ species, which were growing there in the greatest luxuriance from the very summit to a considerable dis- tance down the slopes and gullies of the mountain.-List of the Rhizopoda of New South Wales, by Thomas Whitelegge. The list contains 24 species, with exact localities, and notes on collecting, preserving, and mounting Rhizopods. The species are mostly identical with those found in Europe, America, and India. Amongst those of interest the following may be mentioned:-Arcella dentata, Ehr., Pelomyxa palustris, Greeff, Raphidiophrys elegans, Hert. and Less., Clathrulina elegans, Ceinkowski, and Bionyxa vagans, Leidy.

PARIS

Academy of Sciences, July 19.- M. Jurien de la Gravière, President, in the chair.--Remarks accompanying the presentation of M. de Saint-Venant's important manuscript memoir on " the resistance of fluids," by M. Boussinesq. This unpublished work, begun in 1847 , and not completed till the year 1885 , a short time before the author's death, embodies historical, physical, and practical considerations regarding the problem of the mutual dynamic action of a fluid and a solid, especially in the state of permanence supposed to be acquired by their movements. It comprises three parts, the first dealing with the researches of previous physicists on the impulse of fluids in motion on solil $I$ bodies encountered by them ; the second showing theoretically that this impulse is connected exclusively with the "imperfection of the fluid," that is, the development of friction, which to be surmounted requires a higher pressure on the upper than on the lower surface of the submerged body; the third containing a practical calculation of the impulse experienced by a body in any indefinite fluid current.- On the displacement of ammonia by other bases, and on its quantitative analysis, by MM. Berthelot and André. It is shown that in the presence of soda the double salts yield their ammonia far less readily than the sal ammoniacs unassociated with another base; also that in the ordinary conditions of analyses magnesia is powerless to entirely displace the ammonia. With certain salts, such as ammoniaco-magnesian phosphate, the displacement is extremely slight or nil. These results must henceforth be taken into account in the analysis of earths and of other products containing organic matter associated with the phosphates or with mag. nesia.-On a reindeer's antler embellished with carvings found by M. Eugène Paignon at Montgaudier, by M. Albert Gaudry. This relic of the reindeer age ranks among the most interesting animal and human remains in recent years discovered by M. Paignon in the Montgaudier Caves, Tardoire Valley, Charente. It is pierced with a large hole and covered with carvings executed with such a sure hand and sentiment of form that it shows even to greater advantage under the magnifying glass than when viewed with the naked eye. One face shows $\mathrm{t}$ wo seals (Phoca vitulina and a larger perhaps of different species), a fish (a salmon or trout), and three twigs of plants. On the other side are two long slender animals, apparently eels, three other animal figures exactly alike but indeterminable, and an insect. This specimen of prehistoric art, of the authenticity of which there can be no doubt, has been presented by the finder to the Museum, together with several other objects from his valuable collection. - On the real position to be assigned to the fossil flora of Aix in Provence (continued), by M. G. de Saporta. The conclusion already arrived at on stratigraphic grounds, that this flora belongs to the triple series of the Upper Eocene, Tongrian, and Aquitanian, is here confirmed by the Palæontological indications themselves. - On the development in series of the potential of a homogeneous revolving body, by M. O. Callandreau. - On the variations of the absorption-spectra in non-isotropic mediums, by M. Henry Becquerel. Apart from certain anomalies here described, it may be generally assumed that for each absorption-band there is a single system of three principal rectangular directions, of such a nature that the intensity of a luminous vibration proceeding from a crystal parallel to the direction of the incidental vibration may be represented by the form $I=\left(a \cos ^{2} \alpha+b \cos ^{2} \beta+c \cos ^{2} \gamma\right)^{2}$, where $\alpha, \beta, \gamma$ indicate the angles of direction of the vibration with the principal directions, and $a^{2}, b^{2}, c^{2}$ the principal intensity of the radiation in question. This hypothesis seems to be confirmed by photometric measurements executed with plates of epidote.-On the decomposition of hydrofluoric acid by an electric current, by M. H. Moissan. - Note on urethane regarded from the standpoint of chemical analysis by $\mathrm{M}$. Georges Jacquemin. - Action of some organic chlorides on diphenyl in the presence of the chloride of aluminium, by M. P. Adam.-On the normal propylamines, by M. 
C. Vincent. The results of the author's researches are : (I) The separation of the three normal propylamines ; $(2)$ the discovery of nitrosodipropylamine; (3) the determination of the physical constants of di- and tripropylamine and of nitrosodipropylamine. -On a new creatinine (ethylamido-acetocyamidine), and on the formation of the creatinines and creatines, by M. E. Duvillier. From the author's experiments it follow's, so far, that the action of cyanimide on the starch acids consists essentially in the formation of creatinines, that of crestines taking place only in a very few cases.-On a combination of stannic chloride with hydrochloric acid (chlorostannic acid), by M. R. Engel, - On the alcoholate of potassa, by M. E. J. Maumené. Referring to M. Engel's note in the last issue of the Comptes Rendus, the author points out that he had already determined and announced an alcoholate of potassa so far back as the year 1872 (Les Mondes, December 19, 1872). -- Note on the antennæ of the Eunicians, by M. Et. Jourdan.--On the effects of pollinisation in the orchid family, by M. Léon Guignard. A series of experiments is described which the author has carried out for the purpose of determining the varying interval which intervenes between pollinisation and fertilisation in this group of plants.-On the amphibolic schists and gneiss, and on the limestones of Southern Andalusia, by MM. Ch. Barrois and Alb. Offret.-Fresh experiments with balloon photography : ascent of MM. A. and G. Tissandier and P. Nadar, by M. G. Tissandier. During this ascent, which took place on July 2, and lasted nearly six hours, the altitude never exceeding 1700 metres, M. Nadar took no less than thirty instantaneous photographs; of these about a dozen constitute undoubtedly the finest series of negatives yet obtained from a balloon. Amongst them were two views of Versailles at 800 metres; one of Sèvres at 600 metres ; one of Ballème (Orme) at 900 metres ; several perspectives of SaintRemy (Sarthe), some at I 200 metres. During a second ascent the following week, M. Nadar secured three good views of Champigny and the banks of the Marne. These experiments place beyond all doubt the success of aërial photographic operations.

\section{BERLIN}

Physical Society, June 4.-Dr. Pringsheim spoke on a new application of the telephone for the measurement of electrical resistances, a purpose for which it had already been brought into use by Prof. Kohlrausch in cases in which the resistances were measured by means of alternating currents-in cases, that is, of fluid conductors and also in the case of wires. Dr. Pringsheim had, however, observed that in the measurement of wire-resistances by means of alternating currents the determinations by the telephone did not always concur with those of the galvanometer, and varied very much with repeated measurements. He therefore applied the telephone for measurement by means of a constant current, and that in the following manner. In the Wheatstone bridge the circuit usually occupied by the galvanometer was of constant resistance. The four sides of the wire arrangement contained the wire the resistance of which required to be measured, and the rheostat. The two free angles of the square were connected by a wire circuit in which was placed a telephone. So long as the resistances of the two sides of the bridge were not perfectly equal, a part of the current.flowed through the telephone circuit, and each time this was opened a snapping was heard in the telephone. The rheostat resistance was then changed till nothing was heard on opening the telephone circuit. The sensitiveness of this method was equal to o'04 per cent. of the total resistance. - Prof, von Helmholtz reported on his most recent investigations, which respected the "doctrine of the maximum economy of action," and communicated the interesting history of the understanding of this principle. The doctrine was first propounded by Maupertuis in 1744 in a treatise laid before the Paris Academy. This treatise contained, however, no general statement of the proposition, nor did it define the limits of its applicability, but only adduced an example. This example was, in accordance with the present state of our knowledge, not pertinent, and had no relation to the principle of the actio minima. Two years later Maupertuis propounded his principle before the Berlin Academy, proclaimed it to be a universal law of nature and the first seientific proof of the existence of God. On this occasion, too, he did not prove the proposition nor determine the limits of its applicability, but only supported it by two examples, one of which alone was correct. This principle, propounded with such grand solemnity, but so weakly sup. ported, was violently attacked by König of Leipzig, and just as keenly defended by Euler. This mathematician likewise failed to furnish the proof, which was not possible till after the investigations of Lagrange. The form in which the principle of the activ minima now existed was given to it by Hamilton, and the Hamiltonian principle for ponderable bodies was in complete harmony with the Lagrange propositions. The elder Neumann, Clausius, Maxwell, and the speaker had already extended the Hamiltonian principle to electro-dynamics. For this purpose, and in order to be able to subordinate to it all reversible processes, the speaker had undertaken some transformations of it, and had introduced into it the conception of the "kinetic potential." In the form it had thus attained the Hamiltonian law - the old principle of the actio minima-had in point of fact universal validity. It had just as wide an application as had the law of the conservation of energy, and revealed a whole serie of mutual relations between the different physical processes. In his communication Prof, von Helmholtz gave only a quite general view of his investigations.

\section{BOOKS AND PAMPHLETS RECEIVED}

"Studies from the Biological Laboratories of the Owens College," vol. i (J. E. Cornish, Manchester). " "Exterior Ballistics," by J. M. Ingolls (Van Nostrand).- "Essays relating to Indo-China," 2 vols. (Trübner).- "Fifth
Annual Report of the United States Geological Survey," by J. W. Powell Annual Report of the United States Geological Survey," by J. W. Powell
(Washington). " "The Chemistry of Wheat Flour and Bread," by W. Jago (Washington). " " The Chemistry of Wheat Flour and Bread," by W. Jago (Brighton).- "Annual Report of the University College and Free Library
Committee of the Borough if Nottingham," $1885-86 .-$ "Report on the Pro. Committee of the Borough if Nottingham," $1885-86$.- "Report on the Pro. gress and Condition of the Botanic Garden and Government Plantations of man's School Geography," by G. G. Chisholm (Longmans).- "Annuaine Geologique Universel et Guide du Geologique, 1886," vol, ii., by Dr. Dagin cuurt.- "Proceedings of the American Association held at Philadelphia," 2 parts (Salem). - "The Law of Storms," second edition, by W. H. Rosser (Norie and Wilson).-" Fourth Report of the U.S. Entomological Commission" (Cotton Worm and Boll Worm), by H. Riley (Washington). " "Progress of Astronomy, r885," by W. C. Winlock (Washington). - "Bulletin de la Société Impériale des Naturalistes de Moscou," Nos. 3 and 4 (Moscou). - "Original Mittheilungen aus der Ethoologischen Abtheilung der König lichen Mus. zu Berlin," Erster Jahrgang, Heft r, 2, 3 (Sp trmann, Berlin).

\section{CONTENTS}

Electric Transmission of Energy. By Prof. John

Perry, F.R.S. . . . . . . . . .

Our Book Shelf :-

Tregear's "Aryan Maori" . . . . . . . . .

Letters to the Editor:-

'Tidal Friction and the Evolution of a Satellite.-

James Nolan; Prof. G. H. Darwin, F.R.S. .

Peripatus in Demerara.-John J. Quelch . . . 288

Upper Wind-Currents over the Bay of Bengal in March, and Malaysia in April and May.-Hon. Ralph Abercromby ..........

Mock Sun.-Sir W. J. Herschel . . . . . .

"The Duration of Germ-Life in Water."-Percy

F. Frankland ............

Animal Intelligence.-Hy. Ling Roth . . . .

The Microscope as a Refractor. - L. Bleekrode. .

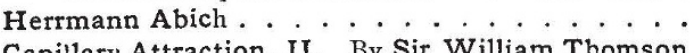

Capillary Attraction, II. By Sir William Thomson,

F.R.S. (Illustrated) . . . . . . . . .

The Science and Art Department Examination in

Chemistry. . . . . . . . . . . . .

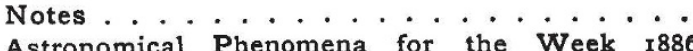

August I -7 . . . . . . . . . . . . .

The Volcanic Eruption in New $Z$ ealand . . . . . 301

Science in New South Wales . . . . . . . . 303

Ice Movements in Hudson's Bay. By Lieut. A. R.

Gordon, R.N.

The Transcaspian Fauna ........ . . 30

Societies and Academies . . . . . . . . 305

Books and Pamphlets Received . . . . . . . 308 